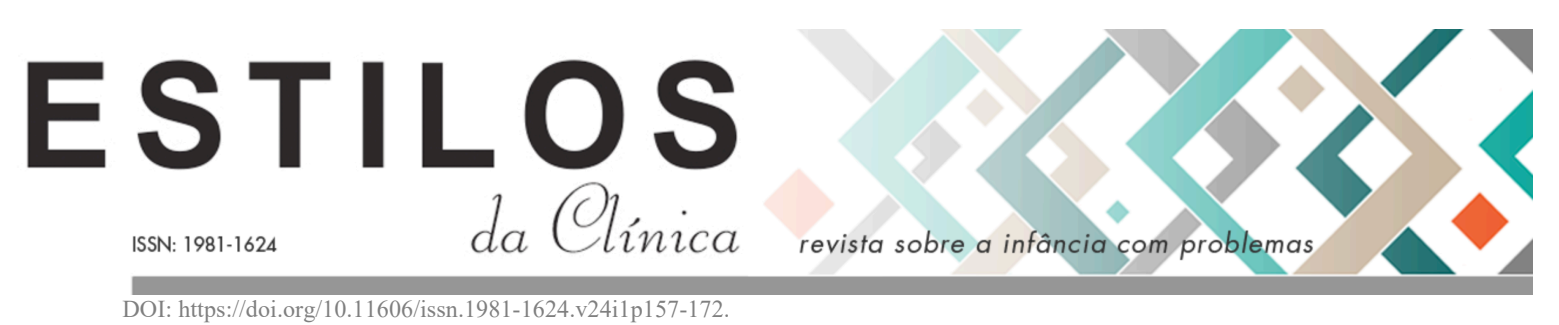

Fundamentos

\title{
O espaço potencial: da origem à evolução
}

\section{Conceição Aparecida Serralha ${ }^{1}$}

Resumo. Estudo sobre o conceito e a teoria do espaço potencial de D. W. Winnicott. Realizou-se uma leitura exaustiva da obra desse autor e de estudiosos dela. Não há consenso entre estes sobre o momento em que o espaço potencial se constitui na linha do amadurecimento do indivíduo e acerca das expressões utilizadas para nomeá-lo. Para Winnicott, o espaço potencial é o locus de um processo que acontece no indivíduo, iniciando-se em uma área intermediária, com seus fenômenos e objetos transicionais, e evolui para o brincar, para o brincar compartilhado e para as experiências culturais.

Palavras-chave: espaço potencial; Winnicott; teoria do amadurecimento; brincar; área de experiências culturais.

\section{El espacio potencial: del origen a la evolución}

Resumen. Estudio sobre el concepto y la teoría sobre el espacio potencial de D. W. Winnicott. Se realizó una lectura exhaustiva de la obra de ese autor y de estudiosos de ésta. No hay consenso entre éstos sobre el momento en que el espacio potencial se constituye en la línea de la maduración del individuo y acerca de las expresiones utilizadas para nombrarlo. Para Winnicott, el espacio potencial es el locus de un proceso que ocurre en el individuo, que se inicia en un área intermedia, con sus fenómenos y objetos transicionales, y evoluciona para el juego, para el juego compartido y para las experiencias culturales.

Palabras clave: espacio potencial; Winnicott; teoría de la maduración; jugar; área de experiencias culturales.

\section{Potential space: from origin to evolution}

Abstract. It is a study on the concept and theory of potential space by D. W. Winnicott. An exhaustive reading of the author's work and her scholars was carried out. There is no consensus among them on the moment when potential space constitutes in the line of maturation of the individual and on the expressions used to name it. For Winnicott, potential space is the locus of a process that happens in the individual, which begins in an intermediate area with its phenomena and transitional objects, and evolves to playing, shared playing and cultural experiences.

Keywords: potential space; Winnicott; maturation theory; playing; area of cultural experiences.

1. Pesquisadora colaboradora (pós-doutorado) do Departamento de Filosofia do Instituto de Filosofia e Ciências Humanas da Universidade de Campinas (IFCH/Unicamp). Professora Associada do Programa de Pós-Graduação em Psicologia da Universidade Federal do Triângulo Mineiro (UFTM), Uberlândia, MG, Brasil. E-mail: serralhac@gmail.com 
$\mathrm{D}$ onald Woods Winnicott, pediatra, psiquiatra infantil e psicanalista inglês, pensava a psicanálise como uma ciência que se desenvolve, mas concordava que isso não era fácil de ser reconhecido por pessoas que se habituavam a ler enunciados psicanalíticos de forma dogmática, tratando-os como algo que não deveria ser modificado. Para Winnicott (1990/1988), a teoria psicanalítica deveria estar em constante desenvolvimento e esse processo deveria ocorrer naturalmente, e de forma semelhante às condições emocionais do ser humano estudado.

Nos trabalhos do Grupo de Pesquisa em Filosofia e Práticas Psicoterápicas (GrupoFPP), tanto na Pontifícia Universidade Católica de São Paulo (PUC-SP) quanto na Universidade Estadual de Campinas (Unicamp), liderado pelo professor Zeljko Loparic, esse pensamento sempre esteve em vigor e, desde os anos 1990, esses estudos têm visto e revisto vários pontos da teoria psicanalítica de Winnicott. Nesse contexto, foi percebida a necessidade de uma compreensão mais apurada de alguns conceitos, a exemplo do conceito e da teoria sobre o espaço potencial. O que torna esse estudo mais complexo é que para ter a dimensão desse conceito, é preciso conhecer também os conceitos de objeto transicional, fenômenos transicionais, experiência, terceira área de experiência e experiência cultural, e o inter-relacionamento entre eles.

De acordo com Winnicott (1971/1975), o espaço potencial existe entre o "objeto subjetivo e o objeto objetivamente percebido", entre "nada haver senão eu e a existência de objetos e fenômenos situados fora do controle onipotente" (p. 139). Desse modo, a princípio, pode-se entender que a criação desse espaço se relaciona a uma mudança que ocorre com o amadurecimento da criança, possibilitando-lhe a saída de uma posição de apenas se relacionar subjetivamente com os objetos, para percebê-los como parte de uma realidade compartilhada com outras pessoas, desenvolvendo a capacidade de usálos.

Ressalta-se que o termo amadurecimento, utilizado neste texto, foi sugerido por Loparic, para dar conta do sentido das expressões "maturational process" ou "development process" utilizadas por Winnicott (cf. Dias, 2012, p. 91) e que o acompanharam em toda a evolução do seu pensamento. Algumas traduções trazem o termo maturação, mas, na língua portuguesa, ele está muito ligado à biologia, à sociologia, entre outros saberes, e não traduz o sentido pessoal dado pelo autor, que implica um potencial herdado, na tendência à integração em um todo unitário (eu), na dependência do ambiente para essa tendência bem se realizar e seguir rumo à independência, e em outros elementos da relação indivíduo-ambiente. Mesmo entre autores psicanalíticos contemporâneos a Winnicott, esse sentido não era encontrado. Atualmente, a sugestão de Loparic tem sido cada vez mais aceita no Brasil e no exterior, e comungando dessa concepção terminológica, o termo será empregado para nomear a teoria psicanalítica winnicottiana desenvolvida durante grande parte da vida desse autor.

Nesse processo de amadurecimento pessoal, o encontro com a qualidade externa dos objetos é propiciado pela agressividade inata à criança, pelo impulso destrutivo em direção ao objeto, que, se após sua destruição como objeto subjetivo - de controle onipotente -, sobrevive, pode ser usado pela criança. A percepção, portanto, do objeto como não eu, como externo ao eu, parece ser o que possibilita a criação do espaço potencial entre a criança e o meio ambiente (o objeto), embora esse espaço aconteça 
apenas se houver um sentimento de confiança da criança em relação ao objeto, que é possibilitado pela sobrevivência - não retaliação - deste aos seus impulsos destrutivos.

Nesse espaço, a criança viverá experiências de todos os tipos: com os objetos, brincando e utilizando-os para "com eles e neles ser criativa"; com as pessoas, permitindo relacionamentos sociais sem a perda da subjetividade; e com a cultura, vivendo experiências que lhe permitirão contribuir para o fundo comum da humanidade (Winnicott, 1975/1971, p. 141). Entretanto, ao localizar uma terceira área, a área da experiência, no espaço potencial (Winnicott, 1971/1996), uma questão emerge: a menos que se possa pensar em uma evolução/transformação do espaço potencial para a terceira área de experiência, não se pode referir um como o outro, ou seja, o espaço potencial não seria, pura e simplesmente, um sinônimo da terceira área de experiência, como muitas vezes é encontrado nos estudos sobre a teoria desse autor, que serão descritos posteriormente.

Por outro lado, se, como afirma Loparic (1995), “O lactente não está 'no' espaço potencial no sentido em que se diz que uma árvore está no jardim, ele é esse espaço" (p. 53), algo se modificará nesse espaço, resultando e como resultado do amadurecimento do lactente. Cabe buscar, assim, o que se transforma/evolui nesse espaço e possibilita os fenômenos transicionais e a evolução destes para o brincar, para o brincar compartilhado e para a terceira área de experiências culturais (Winnicott, (1968/1975).

Winnicott, em seu texto "O destino do objeto transicional", de 1959, aponta uma direção, ao se referir ao encontro de uma terceira área do viver, correspondente aos fenômenos transicionais do bebê que, "na realidade, deles deriva" (1959/1994, p. 47, grifos nossos). Note-se que Winnicott refere derivar dos fenômenos transicionais, não as experiências culturais, mas a terceira área na qual essas experiências culturais podem acontecer. Esta seria o espaço potencial evoluído/transformado? Ou seria uma área de experiência "alojada" no espaço potencial, que poderia ser compreendido como algo mais primitivo, comportando mais do que essa terceira área derivada dos fenômenos transicionais?

A fim de detalhar o sentido dado por Winnicott ao conceito espaço potencial e conhecer o seu destino, foi empreendida uma leitura exaustiva da obra desse autor a partir dos textos em inglês e das traduções brasileiras, bem como de trabalhos dos estudiosos dessa área que discutiram o conceito. Os trabalhos de Winnicott foram acessados através da plataforma Winnipooh, cedida pelo Instituto Brasileiro de Psicanálise Winnicottiana, que conta com todos os textos originais de Winnicott. Por meio dessa plataforma, foram acessados os termos potential space (50 ocorrências), area (539 ocorrências), zone (38 ocorrências), space (155 ocorrências), gap (84 ocorrências), experience (2339 ocorrências), transitional object (310 ocorrências), e transitional phenomena (177 ocorrências). Todas as ocorrências foram analisadas em um esforço hermenêutico para alcançar os objetivos deste estudo.

No tocante aos trabalhos de estudiosos da obra de Winnicott, foram lidos textos de mais de 60 autores, mais especificamente, 37 autores estrangeiros e 29 brasileiros. Esses textos foram encontrados a partir da busca em bases de dados e bibliotecas, pelos termos "espaço potencial", "objeto transicional" e "fenômenos transicionais", em português, inglês e espanhol. Uma quantidade maior de textos foi encontrada, contudo, a seleção levou em conta não somente o tema, mas também os objetivos, ou seja, os textos teriam que discutir a questão da origem e/ou da evolução do espaço potencial e 
não apenas descrevê-lo, ou usá-lo na compreensão de um caso, ou ainda, discutir sua existência como parte do amadurecimento do indivíduo. Após a leitura, os textos que compuseram este artigo foram selecionados por uma adaptação do critério de saturação dos dados, utilizado em pesquisas qualitativas (Turato, 2003): à medida que a compreensão dos autores, no texto lido, se tornava redundante ao que já havia sido encontrado, era realizada mais uma seleção; entre aqueles que se assemelhavam, foi selecionado o texto de publicação anterior aos demais.

O presente artigo traz, portanto, os resultados dessa investigação.

\section{O espaço potencial em sua origem conceitual}

A expressão espaço potencial surgiu bem tarde na obra de Winnicott. A primeira referência a ela é de janeiro de 1967, em uma discussão sobre o desenvolvimento primitivo, na qual expôs a sua teoria sobre o tema, a convite do Clube de 1952 - uma sociedade de analistas britânicos seniores que se reuniam informalmente para discussão de ideias. O trabalho apresentado nessa ocasião foi chamado por Winnicott de "DWW sobre DWW" (1967/1994).

De acordo com Klautau (2007), em 1960, Lacan prenunciou o conceito de espaço potencial, ao se referir ao "lugar" que ele nomeou objeto $a$, antes de Winnicott nomear essa área em sua tentativa de situar no tempo e no espaço o lugar ocupado pelo brincar. Contudo, embora o conceito tenha recebido a denominação de espaço potencial somente em 1967, desde o início da década de 1950, Winnicott já trabalhava a ideia de uma "terceira parte na vida do indivíduo", que ele descreveu como uma "região intermediária da experimentação", para a qual contribuiriam tanto elementos da realidade interna quanto da vida externa. Essa área não deveria ser questionada, mas existir como um lugar em que o indivíduo poderia descansar da tarefa que todo ser humano empreende de separar as realidades interna e externa, mantendo-as assim e, ao mesmo tempo, inter-relacionando-as (1951/1993, p. 318, 1953/1975, p. 15).

Em carta a Roger Money-Kyrle, de 27 de novembro de 1957, ao se referir a essa área intermediária para a qual buscava chamar a atenção, Winnicott reconheceu que a palavra intermediária (intermediate) lhe foi dada por Money-Kyrle. Nesse carta, porém, Winnicott a criticou, apesar de continuar utilizando-a. Havia um temor de que, mesmo sendo uma palavra útil, seu nome ficasse associado a algum tipo de fenômeno estático. Preferia a palavra "transição", por esta implicar movimento, o que era fundamental em sua teorização (1987a/1990a, p. 37).

Entre outras influências sofridas por Winnicott, encontra-se a de sua analista Joan Riviere, referida no texto de 1951, "Os objetos e fenômenos transicionais". Ao pensar sobre a tensão vivida pelo indivíduo por relacionar a realidade interna com a externa, Winnicott se referiu ao alívio que o indivíduo tem em razão de poder viver experiências nessa área intermediária (1951/1993, 1953/1975). No texto de Riviere, publicado em 1936, encontram-se raízes desse pensamento de Winnicott. Inicialmente, ela descreveu o mundo subjetivo do bebê, "não só carente de objetividade, mas sem objetos", corrigindo, posteriormente - em 1950 -, para "sem noção consciente de objetos externos" (1936/1982, p. 52). 
Riviere disse que esse mundo do bebê não possuía objetividade, embora houvesse desde o início um "alicerce na experiência para a objetividade". Por ser tão inicial, esse alicerce só poderia ser pensado como uma sensação corpórea suficientemente intensa, registrada dessa forma, tendo uma realidade para o bebê, que nada poderia alterar ou destruir. Esse tipo de sensação ou percepção era entendida por Riviere (1936/1982) como alicerce da vida de fantasia, apesar de atentar-se ao fato de que "a vida de fantasia nunca é pura fantasia". Para ela, todas as fantasias eram "misturas" de realidade interna e externa, consistindo em "verdadeiras percepções e falsas interpretações" (pp. 52-53).

Winnicott, porém, não chamou a forma subjetiva de o bebê perceber o mundo de "falsas interpretações", pois compreendeu que, para o bebê, no início, não existe falso e verdadeiro, fato e fantasia. $O$ bebê concebe e cria o mundo a partir de uma ilusão nesse sentido, possibilitada pela sustentação de um ambiente facilitador. Essa ilusão somente se dissipará, relativamente, por meio de um "desilusionamento" bem dosado pelo ambiente.

Ao creditar a existência de uma área intermediária imprescindivelmente a uma maternagem suficientemente boa, Winnicott ressaltou a confiabilidade como elemento fundamental na sua constituição. O pensamento de Erikson sobre a formação da identidade (1956) e o de Fred Plaut (1966) o influenciaram. Segundo Erikson, o montante de confiança do bebê na mãe não parece depender das quantidades absolutas de alimentos ou demonstrações de afeto, mas da qualidade da relação que ele estabelece com a mãe. As mães promovem um sentimento de confiança em seus filhos em razão de essa qualidade combinar a satisfação sensorial das necessidades individuais do bebê com um firme sentimento de confiança pessoal, no âmbito do estilo de vida confiante que caracteriza a comunidade em que vivem. Isso vai constituir a base do sentimento de estar "muito bem", de o bebê ser ele mesmo e de chegar a ser o que outras pessoas esperam que ele chegue a ser (Erikson, 1968/1974).

No tocante ao analista junguiano Fred Plaut, Winnicott se alinhava ao seu pensamento quando ele afirmava que a capacidade de formar imagens e recombiná-las construtivamente em novos padrões dependeria da capacidade de o indivíduo confiar (Plaut, 1966). Ao afirmar isso, Plaut diferenciava essa capacidade dos sonhos ou fantasias. Nesse contexto, para Winnicott, a construção da confiança teria por base a experiência vivida pelo bebê - a ilusão de contato - durante a época da dependência absoluta, antes de viver a separação e uma independência relativa (1967/1975).

Na teoria winnicottiana, a experiência ou a capacidade de viver experiências é uma conquista do indivíduo dentro do processo de amadurecimento emocional. Ela não é alcançada sempre por ser dependente da facilitação do ambiente, que pode ou não ocorrer. Na já referida carta a Money-Kyrle, de novembro de 1952, Winnicott (1987/1990a) escreveu: “A experiência é um trafegar constante na ilusão", sempre procurando interagir a criatividade com o que o mundo pode oferecer (p. 38). Se o ambiente pôde ser satisfatório, haverá saúde e uma ilusão de contato do indivíduo com o mundo, e é essa ilusão que será fundamental para os aspectos mais importantes da experiência humana, a exemplo das artes (Winnicott, 1987/1990a).

A descrição de Winnicott dessa área intermediária não foi uma novidade. Para ele, os filósofos e poetas já a reconheciam, a exemplo de Donne, poeta metafísico, teólogo e descendente de Thomas More (Winnicott, 1953/1975, pp. 9-10). De acordo com Guirri (1963/1979), era típico em Donne o paradoxo, a mescla de sentimentos, sendo a 
metáfora um de seus procedimentos mais criticados e, ao mesmo tempo, base de sua renovação poética. Em trechos do poema "El Éxtasis" (Donne, 1633/1979), pode-se reconhecer elementos dessa área intermediária:

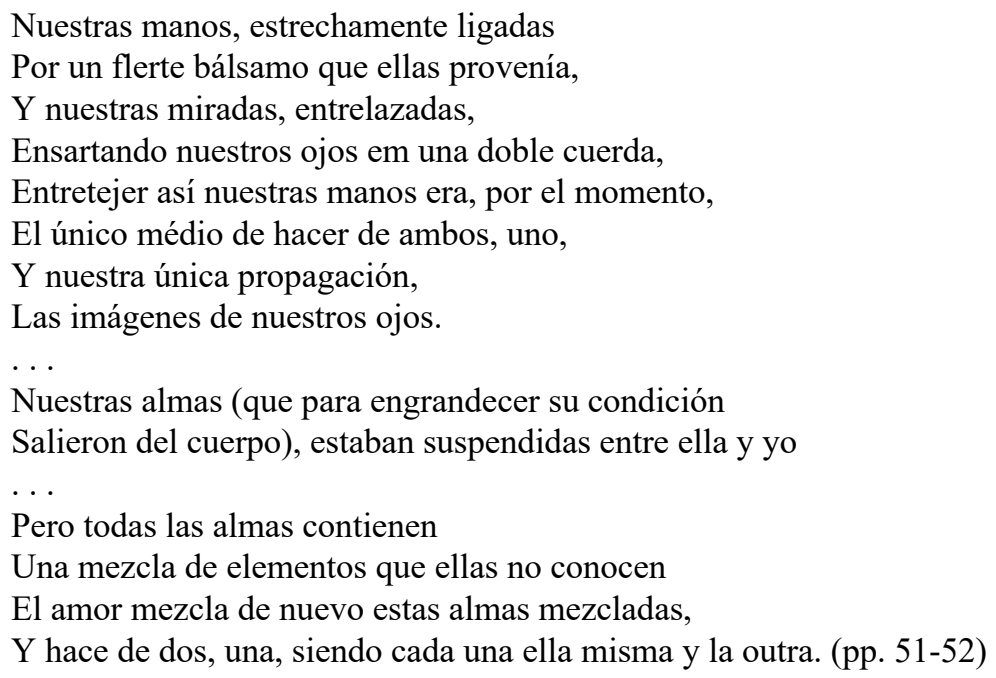

Newman (2003), por sua vez, acreditava que Winnicott faria parte da tradição cultural "romântica", derivando sua ideia do trabalho de Wordsworth e Coleridge sobre as três vidas de pessoas comuns e saudáveis, as quais seriam a vida na realidade externa ou no mundo, a vida na realidade interna ou pessoal e a vida na área da experiência cultural. Newman, além do uso do paradoxo por todos eles, percebia ainda uma outra afinidade: a forma como Wordsworth compreendia a poesia e a forma como Winnicott compreendia o brincar, que vida afora constituiria o lugar das experiências intensas nas artes, na religião, na imaginação e no trabalho artístico criativo (1951/1993/1953/1975).

Em 1967, na época em que criou a expressão espaço potencial, Winnicott, em duas oportunidades, buscou localizá-la. Na primeira, ele a localizou fora da linha que divide o interno do externo, na segunda, a partir de sua experiência pessoal, no interior dessa linha ("on the inside of this line"), chamando esse espaço de "meu clube" (Winnicott, 1969/1994, p. 201). De acordo com a contribuição de Ogden (2014), pode-se entender essa mudança, não como uma substituição da primeira pela segunda, mas como um espaço em que, ao se originar de um espaço físico e mental potencial entre mãe e bebê, no decorrer de um desenvolvimento normal, o bebê, a criança ou o adulto, teria a possibilidade de desenvolver sua própria capacidade de gerar um espaço potencial, constituindo um "conjunto organizado e organizativo de atividades psicológicas operando em um modo particular" (p. 121).

Caso se considere esse entendimento de Ogden - de uma mudança em razão de um desenvolvimento do indivíduo - ou a compreensão de uma mudança advinda de um amadurecimento teórico de Winnicott, pode-se, a partir da segunda localização, compreender melhor tanto a afirmação de Loparic, de que o bebê é esse espaço, quanto duas afirmações de Winnicott (1968/1975): a primeira, de que a área do brincar não é a realidade psíquica interna nem a realidade externa, embora esteja "fora do indivíduo" (p. 76); a segunda, acerca da existência de uma sobreposição de duas áreas do brincar, a do bebê e a de outra pessoa, a do paciente e a do analista, quando a comunicação se estabelece a partir da confiabilidade. Winnicott (1954/1994) considerou que qualquer pessoa tem muito a ganhar com a sobreposição parcial de sua fantasia à de outra pessoa, 
ocorrendo uma experiência partilhada - uma identificação cruzada -, mesmo que não abranja o todo da área do fantasiar. Ao se levar em conta a primeira localização, no entanto, a descrição cria a possibilidade de uma fusão, ou seja, de um espaço comum a ambos, o que parece ter sido a característica do espaço inicial mãe-bebê, e não de espaços pessoais sobrepostos e em comunicação, de um tempo mais tardio.

\section{Estudiosos de Winnicott}

A partir da análise da compreensão de alguns autores sobre o espaço potencial winnicottiano, logo se percebe que, em relação a alguns pontos, não há consenso. Um desses pontos é o que trata do momento em que esse espaço se constitui na linha de amadurecimento do indivíduo: ele está presente desde o início ou se constitui apenas a partir da separação da mãe e do bebê, ou seja, do momento em que o bebê começa a perceber objetivamente a mãe e a si mesmo? Outro ponto é: pode-se entender que as diversas denominações "área de ilusão", "área intermediária", "terceira área de experiência", "área de experiências culturais" e "espaço potencial" se constituem um mesmo fenômeno, podendo ser consideradas sinônimas?

Ogden (2014) afirmou existirem formas específicas de espaço potencial - dentre as quais o espaço do brincar; a área dos objetos e fenômenos transicionais; o espaço analítico; a área da experiência cultural e a área da criatividade -, mostrando que em seu entendimento, apesar das especificidades, todos e cada um são espaços potenciais. Davis e Wallbridge (1981/1982), por sua vez, entendiam que a "área da ilusão" também era denominada "espaço potencial" e, desse modo, ambos - área da ilusão e espaço potencial - se referiam a um mesmo fenômeno. Para eles, este seria um espaço presente antes do surgimento dos objetos transicionais e constituiria "muito mais do que uma área onde a ilusão da onipotência continua a ser servida" (p. 77).

Fulgencio (2016) também pareceu ter essa mesma compreensão ao escrever que, quando a vertente cultural da natureza humana é considerada, esta pode ser entendida como a expansão desse espaço e, nele, o objeto transicional terá origem. Além disso, Fulgencio pensa a potencialidade desse espaço pelo fato de ele poder receber esses objetos que são simultaneamente criados e encontrados pelo indivíduo. Entende-se que, para esse estudioso, o espaço é anterior aos objetos e fenômenos transicionais, uma vez que é nele que estes se originam, bem como é o espaço que tem possibilidade de recebêlos.

Ao destacar os diferentes termos empregados por Winnicott para se referir ao espaço potencial - terceira área, área intermediária, espaço potencial, local de repouso e localização da experiência cultural - Abram (2000) afirmou que, em relação ao desenvolvimento do indivíduo, "os fenômenos transicionais existem desde o início, mesmo antes do nascimento, em relação à díade mãe-bebê" (p. 253). A leitura que essa autora faz do paradoxo de Winnicott é a de que, quando o bebê se separa da mãe, ele preenche o espaço potencial com o brincar e com a experiência cultural. Portanto, para ela, o espaço é anterior à separação do bebê da mãe, pois o que ocorre com a separação é o preenchimento desse espaço, e não a sua origem.

Outros autores, entretanto, compreendem essa questão de modo diferente. Dias (2012) considera que o espaço potencial só surge mais tarde, na fase da 
transicionalidade, e, como Abram, acredita que ele será preenchido no devido tempo pelos fenômenos e objetos transicionais. Green (2013), por sua vez, afirma: "A área intermediária não existe no início" (p. 54), pois se trata de uma tentativa de lidar com o que foi separado, no exato ponto e momento da separação. De forma semelhante, Klautau (2007) escreveu: "O processo de separação possibilita a emergência de um espaço potencial”' (p. 279).

Ao entender que os fenômenos transicionais surgem para aliviar a tensão no bebê, oriunda do contato com a realidade objetiva, Safra (2005) os compreende sob o domínio da ilusão promovida pela adaptação da mãe às necessidades do bebê, e a partir deles emergirá o objeto transicional. Esse autor acredita que, com o desinvestimento do objeto transicional, é que se originará o espaço potencial, no qual a capacidade de viver fenômenos transicionais passa a irradiar para todo o campo cultural. Assim, para Safra, também o espaço potencial só surge após a separação da mãe de seu bebê. Graña (1991), ao dizer que o espaço potencial "alude pontualmente ao tempo e ao espaço de iniciação do estado de separação" (p. 91), também transparece entender que, somente a partir da separação, o espaço se constitui por meio de um processo de "desilusionamento".

Phillips (2006), em seu livro sobre a vida e a obra de Winnicott, mencionou o fato de, em alguns pontos de sua teorização, Winnicott se tornar confuso, "chegando a se contradizer" (p. 173). Pode-se dizer que a dificuldade de acompanhar o pensamento de Winnicott gerou em alguns estudiosos de sua obra também contradições, como foi o caso de Lins. Em 1996, a autora escreveu: "O bebê faz o objeto que está presente na área intermediária, área de ilusão" (p. 118). Com isso, ela permitiu que se entendesse que essa área intermediária era anterior, ou no mínimo, base para o "feitio" do objeto, subjetivo inicialmente, e depois transicional e objetivamente percebido. Entretanto, em 1998 (Lins \& Luz, 1998), ao escrever "O espaço potencial, por eles [objetos transicionais] inaugurado, é um terreno precário, de passagem, onde a onipotência começa a dar lugar à criatividade" (p. 5), ela mostra que esse espaço potencial, se é inaugurado pelos objetos transicionais, não é o mesmo que a área de ilusão, onde os objetos são "feitos" pelo bebê. Na sequência, disse (Lins \& Luz, 1998): "Persistindo ao longo da vida como espaço potencial, o espaço intermediário é o lugar do jogo da criança e de toda experiência cultural..." (p. 18, grifos nossos). Com isso, ela demonstrou entender que há uma modificação na área intermediária inicial em termos de qualidade, que pode ser compreendida como uma evolução, passando a ser entendido como espaço potencial. Mais à frente, porém, ela escreveu: "Para Winnicott, só a partir da constituição de uma área intermediária, momento em que o bebê começa a poder utilizar o objeto, é possível falar de formação de imagem, portanto de representação" (p. $35)$.

Deixando de lado a questão de formar imagens e representações, destaca-se o momento aludido pela autora. Ao associar a constituição de uma área intermediária ao momento em que o bebê começa a utilizar o objeto, pode-se entender que, para essa autora, a área intermediária não se constitui no início, uma vez que esse momento, em que o bebê começa a utilizar objetos, ocorre mais tarde na linha do amadurecimento.

Referindo-se a outros autores, os quais não identificou, Lins (Lins \& Luz, 1998) transcreveu: "o lugar do objeto transicional é denominado área de ilusão e o lugar dos fenômenos culturais - artes, religião etc. - de espaço potencial. De qualquer modo, para 
Winnicott, as duas noções, a área do brincar e o espaço potencial recobrem-se" (p. 46). Nessa análise, portanto, a área de ilusão e o espaço potencial não são a mesma coisa, não se fundem, não há evolução de um para o outro, mas um recobrimento variável, sem que haja extinção ou suplantação de um pelo outro. Porém, ao afirmar que, a "noção de espaço potencial... vem coroar suas sucessivas abordagens [de Winnicott] da área intermediária de experiência entre a realidade interna e a realidade externa" (p. 159), ela já traz uma ideia de evolução.

Para Grolnick (1993), o "espaço intermediário é pré-simbólico, por natureza, e o espaço potencial é simbólico" (p. 100), demonstrando, assim, que, para ele, não se trata de espaços com as mesmas características. Também, para Ogden (1995), o espaço potencial somente surgiria com o início da simbolização. Segundo ele, "o espaço potencial jaz entre o símbolo e o simbolizado" (p. 89), entendendo com isso que, para o símbolo se tornar independente do simbolizado, seria necessário haver um sujeito envolvido no processo de interpretar o que fosse percebendo. Assim, o espaço é criado dentro de uma triangularidade que se forma a partir da diferenciação entre símbolo, simbolizado e sujeito interpretador. Nesse espaço, os seres humanos se sentem realmente vivos, e não, seres simplesmente reativos. Ao compreender o espaço potencial de Winnicott dessa maneira, Ogden (2014) acredita que "o bebê é como o criador e intérprete de seus símbolos" (p. 126).

Em relação à denominação do conceito de espaço potencial, alguns autores utilizam a expressão espaço transicional. É o caso de Abram (2000), Graña (1991), Forlenza Neto (2007), Lejarraga (2012), Rodulfo (2009), Caldwell (1981/2007), Claire Winnicott (1967/1994) e Nasio (1995). Este último explica que o termo transicional vai indicar o lugar e a função dos fenômenos na vida psíquica da criança, os quais se alojam em um espaço intermediário entre as realidades interna e externa. Esse espaço amortece o choque que ocorre quando o bebê, ou a criança pequena, se conscientiza de uma realidade externa repleta de coisas e pessoas, que se relaciona com a interna cheia de suas próprias fantasias. Em razão disso, esse espaço passa também a ter uma qualidade transicional. Para este autor, "o objeto transicional é um sinal tangível da existência do espaço transicional” (p. 195).

Loparic (1995) não concorda com essa expressão, por uma questão de sentido. Para ele, esse espaço é um elemento que compõe o "ser (being) do bebê" e possibilita que ocorra "o 'entre' potencial" no qual várias experiências terão lugar, como, por exemplo, o brincar. Desse modo, esse "entre" potencial não é apenas um espaço; ele é também um espaço-tempo e esse espaço e tempo não têm o sentido que é dado na representação (p. 36).

Em Natureza Humana (1954-1971), Winnicott (1988/1990) forneceu uma outra descrição do espaço potencial, permitindo ver que, de fato, não se pode tomá-lo no sentido dado na representação. Ele o descreveu como "substância intermediária [intermediate substance]" o que é localizado entre o narcisismo primário e a relação de objeto. Essa substância seria representada pelos objetos e fenômenos transicionais, com a característica de unir e separar ao mesmo tempo, como também de ser parte do bebê e do ambiente. Além disso, essa substância continuaria existindo na vida das pessoas adultas, na cultura vivenciada por estas (1990/1988, p. 178).

Desse modo, embora o espaço potencial seja possibilitador de experiências transicionais, ele não pode ser em si transicional, uma vez que nele o indivíduo vive 
experiências diversas, em um processo que envolve elementos subjetivos, transicionais, internos, objetivos e externos, de acordo com o tempo e as necessidades do amadurecimento individual.

\section{O espaço potencial na linha do amadurecimento pessoal}

Ao se pensar em que ponto da linha do amadurecimento do indivíduo o espaço potencial se inicia, pôde ser constatado que, para muitos estudiosos, esse espaço tem início com a percepção do bebê de sua separação da mãe. Em alguns textos de Winnicott, encontra-se a possibilidade dessa compreensão, principalmente se o leitor se apegar à representação de espaço e de área se abrindo a partir de uma separação.

$\mathrm{O}$ que se mostrou consensual, nesses estudos, foi a existência de um processo evolutivo que decorre dos "fenômenos transicionais para o brincar, do brincar para o brincar compartilhado e deste para as experiências culturais" (Winnicott, 1968/1975, p. 76, 1957/1982, pp. 193-194), literalmente exposto nessa passagem. O fator tempo se mostra presente nessa análise e, dessa maneira, para se entender o ponto-tempo em que surge o espaço potencial, tem-se que entender a sua relação com os fenômenos transicionais.

De acordo com Winnicott (1951/1993), os fenômenos transicionais permitem que o ser humano possa dar sentido à ideia de se relacionar com um objeto externo, por representarem "os primeiros estágios do uso da ilusão" (p. 327). Ainda em 1951, no texto "Objetos transicionais e fenômenos transicionais", ao utilizar esquemas para expor suas ideias, inicialmente ele ilustrou o que chamou área de ilusão, que se formaria a partir da adaptação da mãe às necessidades do bebê, fazendo com que este tivesse a ilusão de ser o criador do que necessitava. No segundo esquema, Winnicott (1951/1993, pp. 328-329) deu uma forma à área de ilusão, a de um objeto transicional, para ilustrar a função do objeto e dos fenômenos transicionais, que seria dar partida nas experiências do ser humano em uma região neutra.

Embora o objeto e os fenômenos deem partida nessas experiências, Winnicott, por meio dos esquemas, mostrou a existência da área de ilusão anterior à presença do objeto transicional. Esquematicamente, então, de início é formada a área de ilusão, na qual as experiências seriam nomeadas fenômenos e objetos transicionais que, paradoxalmente, dariam início às experiências nessa região neutra, mais tarde denominada por ele de espaço potencial.

Tem-se, portanto, uma área intermediária de ilusão, que possibilita os fenômenos transicionais, dá forma e se transforma em objeto transicional, permitindo o início de outras experiências nesse espaço potencial. Mais especificamente, em 1955, Winnicott (1955/1999) expôs uma linha evolutiva iniciada em uma área entre a mãe e o bebê, "que é mãe $e$ bebê", em um período anterior à integração. Em suas palavras, se tudo corresse bem, essa área se dividiria, gradualmente, na "parte que o bebê finalmente repudia e [n]a parte que o bebê finalmente reivindica" (pp. 218-219). Contudo, essa área, ao se dividir, não se extinguiria, pois os objetos transicionais, entendidos por ele como resíduos dessa área, fariam persistir aquilo que é criado pelo bebê e, ao mesmo tempo, é

parte da realidade externa. Em outro texto, ele (Winnicott, 1988/1990) afirmou “. . .na verdade, um remanescente dessa substância intermediária continuará existindo na vida 
cultural dos homens e mulheres adultos, justamente ali onde se encontra aquilo que mais claramente distingue os seres humanos dos animais (religião, arte, filosofia)" (p. 178). Portanto, no início, o que existe unicamente é uma área que, do ponto de vista do bebê, tudo abarca, e na qual o bebê experiencia certos fenômenos, que acabam se materializando, inicialmente, na forma de objetos transicionais, e evoluem com o amadurecimento da criança, ao mesmo tempo que possibilitam esse amadurecimento.

Não é somente nesse trecho que Winnicott alude à transformação dessa área intermediária inicial em algo objetivo, sem perder, no entanto, sua associação com a ilusão e a subjetividade. Em 1968, ele (1987/1999) afirmou:

A interação da mãe com seu bebê resulta em uma área que poderíamos chamar de território comum, [eu digo o terreno de Tom Tiddler $]^{1}$, a terra de ninguém que na verdade é de cada um, o lugar onde se oculta o mistério, o espaço potencial que pode se transformar em objeto transicional, o símbolo da confiança e da união entre o bebê e a mãe, uma união que não envolve a interpenetração. (p. 89, grifos nossos)

Nesse trecho, nota-se Winnicott claramente a nomear o espaço inicial, a área de ilusão, com a expressão espaço potencial, e, ainda, que este se transforma, evolui. Podese entendê-lo, então, como um espaço que precede e dá condições para o surgimento dos fenômenos e objetos transicionais, e todas as suas derivações.

Para Winnicott (1966/1996), apesar de, inicialmente, o bebê não ter amadurecimento suficiente para perceber a separação de forma não traumática, nas relações com objetos subjetivos do início há uma percepção objetiva, embora com uma capacidade de percepção rudimentar, incipiente e limitada. O bebê, assim, precisa continuar a se relacionar com objetos subjetivos criados por ele. Isso se torna possível em razão de o ambiente facilitador lhe permitir uma experiência de onipotência, da qual irá derivar a "adaptação ao princípio de realidade", o relacionamento com objetos objetivamente percebidos (1963/1990, p. 164). Desse modo, segundo Winnicott (1971/1975), seria útil que se pensasse em uma terceira área do viver do homem, um "viver intermediário", "ocupando um espaço potencial, a negar a idéia de espaço e separação entre o bebê e a mãe, e todos os desenvolvimentos derivados desse fenômeno" (p. 152). Para ele (1967/1996), "havendo saúde, não há separação", uma vez que essa área intermediária de espaço-tempo acabará por se firmar e evoluir para uma rica vida cultural (pp. 28-29).

Ao tentar localizar essa área de experiência cultural, Winnicott propôs seu início no espaço potencial existente entre a criança e a mãe, desde que a criança estivesse certa de que a mãe não lhe faltaria caso necessitasse; portanto, em um ambiente altamente confiável. Localizando-se no espaço potencial - expressão com a qual ele passou a nomear a área de ilusão -, a área de experiências culturais surgiria mais tarde na linha do amadurecimento, tanto que, em textos importantes de sua obra, Winnicott (1959/1994, p. 48; 1967/1975, p. 142) aponta a derivação da área de experiências culturais dos fenômenos transicionais, uma "área intermediária cujo ancestral é o objeto de transição do bebê" (1963/1990, p. 168, grifo nosso). Se Winnicott nomeia a área de ilusão de espaço potencial e se a partir dela os objetos transicionais tomam forma, a que deriva destes e dos fenômenos transicionais, e que permite ao indivíduo viver experiências culturais, não pode ser simplesmente outra forma de nomear o espaço potencial. Outro ponto que nos permite confirmar o surgimento tardio dessa área de

Trecho suprimido da edição em português. 
experiência cultural é sua afirmação de que "há uma idade antes da qual o objeto transicional não pode existir, por causa da imaturidade do lactente" (1957/1990, p. 102). Se a área de experiências culturais deriva dos fenômenos e objetos transicionais e se estes somente passam a existir em um momento mais amadurecido da criança, essa área não é a mesma do início.

Ao expor sobre o brincar, Winnicott, mais uma vez permite entender que o espaço potencial é bem mais inicial, e não surge, para o indivíduo, apenas com a simbolização, como alguns estudiosos o compreenderam. O autor (1968/1975) disse que o brincar “pertence ao espaço potencial existente entre (o que era a princípio) bebê e figura materna, com o bebê em estado de dependência quase absoluta e a função adaptativa da figura materna tida como certa pelo bebê" (p. 76). Parece ser em razão desse processo evolutivo, que Winnicott (1967/1975) afirmou que o espaço potencial "pode ou não entrar em evidência como área vital na vida psíquica da pessoa em desenvolvimento" (p. 140). Ou seja, nele, os fenômenos e objetos transicionais poderão ou não evoluir para o brincar e o brincar compartilhado, e deste para as experiências culturais.

\section{O espaço potencial e outras expressões}

A partir das análises e discussões empreendidas neste texto, as expressões "área de ilusão", "área intermediária", "área intermediária de experiência" e "espaço potencial" podem ser tomadas como sinônimas, desde que o espaço potencial seja compreendido como a área inicial mãe $e$ bebê, e a área de ilusão seja nomeada com toda a sua potencialidade. Já a expressão "terceira área de experiência" não poderia ser utilizada para definir a área inicial, uma vez que, para o bebê, a sua existência como terceira área não ocorre no início. Para sua ocorrência, o bebê teria que ter como pressuposto a existência das duas outras áreas: o mundo interno e o mundo externo. Além disso, essa terceira área de experiências seria derivada dos fenômenos e objetos transicionais, portanto, posterior a eles. Esses objetos, estando na ancestralidade dessa terceira área, demarcam um processo evolutivo, iniciado com a constituição do espaço potencial. A partir da terceira área se iniciaria o brincar, que evoluiria, se tudo corresse bem, para as experiências culturais. Desse modo, a terceira área de experiências ou área de experiências culturais, stricto sensu, não poderia ser a mesma do início, mas uma derivação desta.

Pode ser que a melhor forma de se compreender a teorização de Winnicott, seja tomar o espaço potencial como o locus de um processo psíquico evolutivo, sustentado por um ambiente facilitador e que constitui inicialmente uma área intermediária, que é mãe $e$ bebê - área de ilusão -, onde os fenômenos transicionais passam a ocorrer, podendo se materializar em objetos transicionais, com ambos - fenômenos e objetos evoluindo, no interior da linha que divide o interno do externo, para o brincar, para o brincar compartilhado e, na sequência, para as experiências culturais. Dessa maneira, todo o processo ocorreria no espaço potencial, ao mesmo tempo que se consistiria no espaço potencial, não podendo nenhuma parte desse processo ser entendida única e exclusivamente como esse espaço. A área de experiências culturais seria o último estágio desse processo - sem qualquer característica de total estabilidade -, que nem todos os indivíduos alcançariam, embora apenas aos humanos isso fosse possível. 
Segundo Winnicott (1971/1975), “a extensão desta terceira área pode ser mínima ou máxima, de acordo com a soma das experiências concretas" (p. 148).

Desde o início de sua teorização, Winnicott entendia que o viver nesse espaço se caracterizava pelo fato de as pessoas ficarem aliviadas, poderem descansar e estarem, nele, "livre[s] da tarefa de distinguir o fato da fantasia" (1987b/1990b). Essa é exatamente a característica que impossibilita, por exemplo, uma analogia desse espaço com o virtual da internet (Romão-Dias \& Costa, 2012, Mendes, 2015), uma vez que, neste, mesmo que se possa expressar subjetividade e criatividade e manter comunicação com outras pessoas, está-se sempre sujeito a certas regras e cobrado a definir o que é fato e o que não é.

\section{Considerações finais}

As várias formas de definir, interpretar e descrever a teoria sobre o espaço potencial de Winnicott, encontradas nos vários autores investigados, não contêm propriamente erros. As diferenças encontradas podem ser creditadas a características subjetivas da formação e do percurso profissional de cada autor, bem como ao acesso que tiveram ao tema na obra winnicottiana. Além disso, não se pode dizer que a leitura feita neste estudo consegue abarcar o todo do pensamento de cada autor. Um exemplo é o de Grolnick (1993): o fato de se ter constatado em seu texto que o espaço intermediário e o espaço potencial não apresentavam as mesmas características não pernite inferir que não houvesse, para ele, uma evolução de um para o outro.

Constata-se, na leitura desses autores da obra de Winnicott, que o que eles conseguiram foi apenas uma aproximação do pensamento do autor - uns mais, outros menos -, uma vez que, mesmo que ele ainda estivesse vivo, não haveria garantia alguma de uma identidade total de pensamento nos esclarecimentos que ele pudesse vir a fornecer. $\mathrm{O}$ mesmo pode ser dito em referência à leitura feita dos textos dos vários autores citados neste estudo, o que aponta para a importância de novas investigações sobre o tema e objetivos. Mesmo o que pôde ser inferido como contraditório no pensamento de Lins (Linz, 1996, Lins \& Luz, 1998), por exemplo, pode também ser lido como mudanças no pensamento da autora a partir de contatos com diferentes pontos da obra em estudo. Um exercício importante e necessário ao aprofundamento teórico.

O texto de Winnicott, apesar de confuso em algumas partes, como referido por Phillips (2006), vai permitindo, à medida que se familiariza com o estilo de escrever do autor, a percepção de pontos que orientam a leitura de outros, para uma melhor compreensão do que está sendo comunicado. Da mesma forma que, quando se utiliza o termo "si mesmo" (self), sempre será preciso esclarecer se a referência é a um si mesmo integrado e unitário, ou a uma parte dele. Também, em relação ao espaço potencial, ao tomá-lo como locus de um processo psíquico evolutivo, ele deverá ser citado acompanhado de um esclarecimento da parte, fase, ou momento do processo que está sendo referido, se à área de ilusão ou à área intermediária de experiência, aos fenômenos e objetos transicionais, à terceira área de experiência, ao brincar, ao brincar compartilhado ou à área de experiências culturais. Cada momento tem conquistas específicas, mas, mesmo assim, as características de todos os momentos, em certa 
medida, permanecem e podem ser recuperadas, conforme a necessidade. Trata-se dos resíduos ou dos elementos remanescentes referidos por Winnicott ou, ainda, de um processo de regressão.

Se o espaço potencial for pensado apenas como uma expressão que nomeia a área de ilusão, ou que somente se inicia com a simbolização e vem nomear a área de experiências culturais, perde-se toda a noção e a riqueza desse processo evolutivo. Pensar o espaço potencial como o locus de um processo psíquico evolutivo permite uma aproximação da ideia de Loparic (1995) de que esse espaço é o bebê (e a criança, e o adolescente e o adulto) no tempo.

\section{Referências}

Abram, J. (2000). A linguagem de Winnicott. Rio de Janeiro, RJ: Revinter.

Caldwell, L. (2007). Winnicott and the Psychoanalytic Tradition. London: Karnac Books.

Davis, M., \& Wallbridge, D. (1982). Limite e espaço. Rio de Janeiro, RJ: Imago. (Trabalho original publicado em 1981)

Dias, E. O. (2012). A teoria do amadurecimento de D. W. Winnicott. São Paulo, SP: DWW

Donne, J. (1979). El Éxtasis. In W. Shand, \& A. Guirri (Orgs.), Poemas de John Donne (pp. 51-53). Caracas: Fundarte. (Trabalho original publicado em 1633)

Editorial.

Erikson, E. H. (1974). Identidad, juventude y crisis. Buenos Aires: Paidós. (Trabalho original publicado em 1968)

Forlenza Neto, O. (2007). Constituição do si-mesmo e transicionalidade. In M. C. Pinto (Org.), O livro de ouro da psicanálise: o pensamento de Freud, Jung, Melanie Klein, Lacan, Winnicott e outros (pp. 405-412). Rio de Janeiro, RJ: Ediouro.

Fulgencio, L. (2016). Por que Winnicott? São Paulo, SP: Zagodoni.

Graña, R. B. (1991). Os Objetos da Cultura. In J. Outeiral, \& R. B. Graña (Org.), Donald W. Winnicott: estudos (vol. 1, pp. 88-93). Porto Alegre, RS: Artmed.

Green, A. (2013). Brincar e reflexão na obra de Winnicott. São Paulo, SP: Zagodoni.

Grolnick, S. (1993). Winnicott: o trabalho e o brinquedo. Porto Alegre, RS: Artmed.

Guirri, A. (1979). Prólogo. In W. Shand, \& A. Guirri (Orgs.), Poemas de John Donne (pp. 0709). Caracas: Fundarte. (Trabalho original publicado em 1963)

Klautau, P. (2007). Winnicott e Lacan: a importância do conceito de objeto transicional na formulação do objeto $a$. In B. Bezerra Junior, \& F. Ortega, Winnicott e seus interlocutores (pp. 269-287). Rio de Janeiro, RJ: Relume Dumará.

Lejarraga, A. L. (2012). O amor em Winnicott. Rio de Janeiro, RJ: Garamond.

Lins, M. I. A. (1996). A ilusão e o uso criativo dos objetos. In I. F. M. Catafesta (Org.), D. W. Winnicott na Universidade de São Paulo (pp. 117-130). São Paulo, SP: IP-USP.

Lins, M. I. A., \& Luz, R. (1998). D. W. Winnicott: Experiência clínica \& experiência estética. Rio de Janeiro: Revinter.

Loparic, Z. (1995). Winnicott e Heidegger: afinidades. Boletim de Novidades, (69), 53-60.

Mendes, R. (2015). Smartphones: objeto transicional e conectividade de um novo espaço potencial. Estudos de psicanálise, (44), 133-144. 
Nasio, J.-D. (1995). Introdução às obras de Freud, Ferenczi, Groddeck, Klein, Winnicott, Dolto e Lacan. Rio de Janeiro, RJ: Zahar.

Newman, A. (2003). As ideias de D. W. Winnicott: um guia. Rio de Janeiro, RJ: Imago.

Ogden, T. H. (1995). Sobre o espaço potencial. In P. L. Giovacchini (Org.), Táticas e técnicas psicanalíticas: D. W. Winnicott (pp. 79-95). Porto Alegre, RS: Artmed.

Ogden, T. H. (2014). On potencial space. In M. B. Spelman, \& F. Thomson-Salo (Eds.), The Winnicott tradition: lines of development - evolution of theory and practice over the decades (pp. 121-133). London: Karnac Books.

Phillips, A. (2006). Winnicott. Aparecida, SP: Ideias \& Letras.

Plaut, F. (1966). Reflections about not being able to imagine. Journal Analythic Psychology, $11(2), 113-133$.

Riviere, J. (1982). Sobre a gênese do conflito psíquico nos primórdios da infância. In J. Riviere (Org.), Os progressos da psicanálise (pp. 48-78). Rio de Janeiro, RJ: LTC. (Trabalho original publicado em 1936)

Rodulfo, R. (2009). Trabajos de la lectura, lecturas de la violencia. Buenos Aires: Paidós.

Romão-Dias, D., \& Costa, A. M. N. (2012). O Brincar e a realidade virtual. Cadernos de Psicanálise, 34(26), 85-101.

Safra. G. (2005). Revisitando Piggle. São Paulo, SP: Sobornost.

Turato, E. R. (2003). Tratado de metodologia da pesquisa clínico-qualitativa: construção teórico-epistemológica, discussão comparada e aplicação nas áreas de saúde e humanas. Petrópolis, RJ: Vozes.

Winnicott, C. (1994). Introdução. In C. Winnicott, R. Shepherd, \& M. Davis (Orgs.), Explorações psicanalíticas: D. W. Winnicott. Porto Alegre, RS: Artmed. (Trabalho original publicado em 1967)

Winnicott, D. W. (1975). A localização da experiência cultural. In D. W. Winnicott, O brincar e a realidade (pp. 152-164). Rio de Janeiro, RJ: Imago. (Trabalho original publicado em 1967)

Winnicott, D. W. (1975). O brincar e a realidade. Rio de Janeiro, RJ: Imago. (Trabalho original publicado em 1971)

Winnicott, D. W. (1975). O brincar: uma exposição teórica. In D. W. Winnicott, O brincar e a realidade (pp. 65-87). Rio de Janeiro, RJ: Imago. (Trabalho original publicado em 1968)

Winnicott, D. W. (1975). O lugar em que vivemos. In D. W. Winnicott, O brincar e a realidade (pp. 165-174). Rio de Janeiro, RJ: Imago. (Trabalho original publicado em 1971)

Winnicott, D. W. (1975). Objetos transicionais e fenômenos transicionais. In D. W. Winnicott, O brincar e a realidade (pp. 10-47). Rio de Janeiro, RJ: Imago. (Trabalho original publicado em 1953)

Winnicott, D. W. (1982). Primeiras experiências de independência. In D.W. Winnicott, $A$ criança e seu mundo (pp. 189-195). Rio de Janeiro, RJ: Guanabara Koogan. (Trabalho original publicado em 1957)

Winnicott, D. W. (1990). Natureza Humana. Rio de Janeiro: Imago. (Trabalho original publicado em 1988)

Winnicott, D. W. (1990a). Carta 26, para Roger Money-Kyrle, 27/11/1952. In D. W. Winnicott, $O$ Gesto Espontâneo (pp. 34-38). São Paulo, SP: Martins Fontes. (Trabalho original publicado em 1987) 
Winnicott, D. W. (1990b). Carta 74, para Vitor Smirnoff, 19/ 11/1958. In D.W. Winnicott, $O$ Gesto Espontâneo (pp. 105-108). São Paulo, SP: Martins Fontes. (Trabalho original publicado em 1987)

Winnicott, D. W. (1990b). Comunicação e falta de comunicação levando ao estudo de certos opostos. In D. W. Winnicott, $O$ ambiente e os processos de maturação: estudos sobre a teoria do desenvolvimento emocional (pp. 163-174). Porto Alegre, RS: Artmed. (Trabalho original publicado em 1963)

Winnicott, D. W. (1990b). Sobre a contribuição da observação direta da criança para a psicanálise. In D. W. Winnicott, $O$ ambiente e os processos de maturação: estudos sobre a teoria do desenvolvimento emocional (pp. 101-105). Porto Alegre, RS: Artmed. (Trabalho original publicado em 1957)

Winnicott, D. W. (1993). Objetos transicionais e fenômenos transicionais. In D. W. Winnicott, Textos selecionados: da pediatria à psicanálise (pp. 316-331). Rio de Janeiro, RJ: Francisco Alves. (Trabalho original publicado em 1951)

Winnicott, D. W. (1994). A experiência mãe-bebê de mutualidade. In C. Winnicott, R. Shepherd, \& M. Davis (Orgs.), Explorações psicanalíticas: D. W. Winnicott (pp. 195-202). Porto Alegre, RS: Artmed. (Trabalho original publicado em 1969)

Winnicott, D. W. (1994). O brinquedo na situação analítica. In C. Winnicott, R. Shepherd, \& M. Davis (Orgs.), Explorações psicanalíticas: D. W. Winnicott (pp. 24-25). Porto Alegre: Artmed. (Trabalho original publicado em 1954)

Winnicott, D. W. (1994). O destino do objeto transicional. In C. Winnicott, R. Shepherd, \& M. Davis (Orgs.), Explorações psicanalíticas: D. W. Winnicott (pp. 44-48). Porto Alegre: Artmed. (Trabalho original publicado em 1959)

Winnicott, D. W. (1994). Pós-escrito: D.W.W. sobre D. W. W. In C. Winnicott, R. Shepherd, \& M. Davis (Orgs.), Explorações psicanalíticas: D. W. Winnicott (pp. 433-444). Porto Alegre, RS: Artmed. (Trabalho original publicado em 1967)

Winnicott, D. W. (1996). A criança no grupo familiar. In D. W. Winnicott, Tudo começa em casa (pp. 101-110). São Paulo, SP: Martins Fontes. (Trabalho original publicado em1966)

Winnicott, D. W. (1996). O conceito de indivíduo saudável. In D. W. Winnicott, Tudo começa em casa (pp. 17-30). São Paulo, SP: Martins Fontes. (Trabalho original publicado em 1971)

Winnicott, D. W. (1999). A comunicação entre o bebê e a mãe e entre a mãe e o bebê: convergências e divergências. In D. W. Winnicott, Os bebês e suas mães (pp. 79-92). São Paulo, SP: Martins Fontes. (Trabalho original publicado em 1987)

Winnicott, D. W. (1999). Influências de grupo e a criança desajustada: o aspecto escolar. In D. W. Winnicott, Privação e delinquência (pp. 215-226). São Paulo, SP: Martins Fontes. (Trabalho original publicado em 1955)

Recebido em maio/2018 - Aceito em março/2019. 